\title{
Efectos beneficiosos de la suplementación prenatal con hierro
}

\section{Beneficial effects of prenatal iron supplementation}

\section{Objetivo}

Resumir la evidencia sobre el uso de hierro prenatal , así como sus efectos hematológicos y adversos durante el embarazo.

\section{Diseño}

Revisión sistemática y metanálisis.

\section{Estudios incluidos}

Ensayos aleatorizados que hubieran evaluado la eficacia del uso de hierro prenatal para prevenir la anemia materna y cohortes prospectivas que hubieran evaluado dicha asociación.

\section{Medición de resultados principales}

En los ensayos clínicos, se utilizó el modelo Der Simonian y Laird para la estimación resumida del efecto global del hierro,
Batool A y col. BMJ 2013; 346:f3443 doi: 10.1136/bmj.f3443 realizando un análisis de sensibilidad y explorando la fuente de heterogeneidad entre los subgrupos preespecificados.

Para los estudios de cohorte se utilizó como medida de resumen el $\mathrm{OR}^{*}$ con un análisis ajustado para posibles variables confundidoras.

\section{Resultados}

Fueron incluidos 48 ensayos clínicos (17793 mujeres) y 44 estudios de cohortes (1851682 mujeres).

Como se puede ver en la tabla 1, el uso de hierro aumentó la concentración de hemoglobina media materna en comparación con el grupo control y redujo significativamente el riesgo de anemia materna, la deficiencia de hierro, la anemia por deficiencia de hierro y el bajo peso al nacimiento.

Tabla1. Efecto de la suplementación prenatal con hierro documentado en ensayos clínicos.

\begin{tabular}{l|l|c|c}
\multicolumn{2}{l|}{} & \multicolumn{1}{c|}{$\begin{array}{c}\text { Diferencias en la medida del } \\
\text { peso RR e IC95\% }\end{array}$} & Heterogeneidad (I2) \\
\hline \multirow{2}{*}{$\begin{array}{l}\text { Resultados hematológicos } \\
\text { durante el tercer trimestre } 0 \text { al } \\
\text { nacimiento }\end{array}$} & $4,59(3,72$ a 5,46$)$ & 0 \\
\cline { 2 - 4 } & Hemoglobina materna (g/l) & $0,50(0,42$ a 0,59) & 83 \\
\cline { 2 - 4 } & Anemia & $0,59(0,46$ a 0,79) & 79 \\
\cline { 2 - 4 } $\begin{array}{l}\text { Resultados durante el embarazo } \\
\text { y el parto }\end{array}$ & Anemia por deficiencia de hierro & $0,40(0,26$ a 0,60) & 33 \\
\cline { 2 - 4 } & Bajo peso al nacimiento & $0,81(0,71$ a 0,93) & 0 \\
\cline { 2 - 4 } & Edad gestacional (semanas) & $0.11(-0.35$ to 0.57$)$ & 0 \\
\cline { 2 - 4 } & Parto prematuro & $0,84(0,68$ a 1,03$)$ & 59 \\
\cline { 2 - 4 } & Baja edad gestacional al nacimiento & $0,85(0,67$ to 1,08$)$ & 0 \\
\hline
\end{tabular}

El análisis de los estudios de cohortes mostró una mayor incidencia de bajo peso al nacer (OR 1,29; IC95\% 1,09 a 1,53) y de embarazos con parto pretérmino (OR 1,21; 1,13 a 1,30).

Por último, se evidenció un efecto "dosis-respuesta" ya que por cada $10 \mathrm{mg}$ de aumento en la dosis diaria de (hasta un máximo de $66 \mathrm{mg} / \mathrm{día}$ ), se observó una disminución promedio del riesgo de anemia materna (RR 0,88; 0,84 a 0,92); un incremento del peso al nacer de $15,1 \mathrm{~g}(6,0$ a 24,2$)$, y una reducción de la incidencia de bajo peso al nacer de un $3 \%$ (RR 0,97; 0,95 a 0,98).

La duración del tratamiento no se asoció en forma significativa con los resultados después del ajuste de dosis. Por otra parte, por cada aumento de $1 \mathrm{~g} / \mathrm{L}$ de la media de hemoglobina, se incrementó el peso al nacer en $14 \mathrm{~g}(6,8$ a 21,8), sin evidenciarse asociación con la incidencia de bajo peso ni de parto prematuro.

Fuente de financiamiento: No referida.

\section{Comentario}

Dado que en nuestro medio un $20 \%$ de las mujeres en edad fértil no consume la dosis recomendada de hierro alimentario y un $60 \%$ tiene un consumo deficiente durante su embarazo; se recomienda administrarles una dosis diaria de $60 \mathrm{mg}$ de Hierro elemental (como Sulfato Ferroso) más $0,5 \mathrm{mg}$ de Ácido fólico durante el segundo y tercer trimestre hasta el término del embarazo".

El presente metanálisis resume la evidencia disponible sobre el uso de hierro prenatal, avalando la recomendación de suplementos de hierro durante el embarazo. Lamentablemente y debido a la escasez de datos disponibles, los autores de esta investigación no pudieron evaluar la asociación entre la admi- nistración de hierro prenatal y otros resultados más duros como la muerte fetal, perinatal o materna. Asimismo, la heterogeneidad entre varios de los estudios identificados obliga a ser cauteloso en la interpretación de sus resultados.

\section{Conclusiones del comentador}

A pesar de las limitaciones mencionadas previamente, el uso del hierro prenatal mostró ser una estrategia preventiva accesible y eficaz para promover la salud materna e infantil.

Francisco Peper [ Servicio de Medicina Familiar y Comunitaria del Hospital Italiano de Buenos Aires francisco.peper@hospitalitaliano.org.ar]

Peper F. Efectos beneficiosos de la suplementación prenatal con hierro. Evid Act Pract Ambul. Ene-Mar 2014;17(1):16. Comentado de: Batool A y col. Anaemia, prenatal iron use, and risk of adverse pregnancy outcomes: systematic review and meta-analysis. BMJ 2013;346:f3443 doi: 10.1136/bmj..ł3443.

\section{Referencia}

1. Ministerio de Salud, Presidencia de la Nación. Recomendaciones para la Práctica del Control preconcepcional, prenatal y puerperal. Edición 2012. Disponible en URL: http://www.msal.gov.ar/promin/archivos/htm/perin_guias.htm 